\title{
STUDY OF THE STUDENT WORKLOAD PER DAY IN WORKING WITH COMPUTERS
}

\author{
M. Albert* \\ Medical College "Y. Filaretova", Medical University - Sofia, Sofia, Bulgaria
}

\begin{abstract}
Student everyday work is unthinkable without the use of a computer. The human body has several systems that allow it to adapt its posture to the environment. The present study examines the posture that students maintain when working with computers.

The purpose of the study is to determine how many hours a day students majoring in rehabilitation work with a computer. Are they familiar with the correct ergonomic posture while implementing these activities.

Methods: For the purposes of this analysis, 72 people were interviewed. The sample was determined in accordance with the accessibility of the participants involved. The survey includes first, second and third year students majoring in specialty "Rehabilitator" at the Medical College "Yordanka Filaretova", Medical University - Sofia. The study is conducted in the last week of April 2020.

The results of this survey show that $95 \%$ of respondents do not use a specialized program to monitor the duration of work with a computer. Only $2 \%$ do not have computers and all use mobile phones.

Conclusion: The stay of students in front of computers that are used for different purposes has been significantly increased. This is a serious precondition for systemic hypodynamics, posture disorders and visual analyser overloading.
\end{abstract}

Key words: computers, body posture, rehabilitator, discomfort, pain

\section{INTRODUCTION}

All young people use computers every day. The epidemiological situation in the world as well as in Bulgaria has forced all school institutions to switch to distance learning. The student daily life during the last three months has been bound up with a long stay in front of their computers (1). Hypodynamics and incorrect posture when working with a computer turn out to be a serious precondition for the occurrence of postural disorders. Characteristic when working with a computer is the static load of the musculoskeletal system from the static working position (2). The upper limbs perform many movements, which puts strain on the cervical spine, pain occurs in the paravertebral muscles, shoulders, forearms and wrists (3).

\footnotetext{
*Correspondence to: Mariana Albert, Medical University - Sofia, Medical College "Y. Filaretova" Sofia "Y. Filaretova "№ 3, bp. 1606 GSM: 0893396597, andial@mail.bg
}

Improper use of computers in unsuitable workplaces can cause visual complaints such as redness of the eyes, blurred vision, dry eyes, burning sensation and headache. (4). Lighting is a major factor that affects the health of the eyes and maintains good eyesight (5). Studies by N. Kozeis (6) prove that tears evaporate with greater intensity when working with a computer. The analysis of the data obtained during Balichev's research shows that a significant percentage of students are not aware of the harmful effects on health that can occur when working with a computer for too long. Prolonged exposure to the computer causes a decrease in visual acuity and impaired visual accommodation. (7). The intensity of the light and the way of lighting are considered more and more important, as they provide good visibility of the objects, which reduces the visual tension, increases the working capacity, slows down the onset of fatigue, the work performed is more efficient and safer. 
Unlike employees in various companies, who are provided with appropriate lighting and chairs that are suitable for long-term work, students work with laptops and use them predominantly in the home environment. Laptops are technologically designed to be used for short periods of time. The monitor and the keyboard are very close to each other, which is a prerequisite for very serious postural disorders. To see the monitor well and work on the keyboard, the muscles of the cervical spine, arms and shoulder girdle are tensed (8).

An important point in the prevention of postural disorders is to raise the awareness of health care professionals so that these conditions can be identified early and treated in a timely manner.

The purpose of this study is to determine how many hours a day students majoring in rehabilitation work with computers and the duration of them to what extent is the cause of hypodynamics. If young people are familiar with the correct ergonomic posture, suitable for this type of work. How students recover from computer fatigue. What complaints are observed as a result of static posture of the body.

\section{MATERIALS AND METHODOLOGY}

The study is conducted in the last week of April 2020. For the purposes of the empirical sociological research a questionnaire was used which includes 12 closed questions divided into four directions:

- types of computer configuration

- time duration when working with a computer

- presence of motor activity

- localisation of pain

For the purposes of this analysis, 72 people were interviewed. The sample was determined in accordance with the accessibility of the participants involved. The survey includes first, second and third year students majoring in specialty "Rehabilitator" at the Medical
College "Yordanka Filaretova", Medical University - Sofia.

The questions have been designed for collecting information in the following fields:

- To study the average duration of work with computers and to what extent it might be the cause of hypodynamics.

-To establish how students recover from fatigue after working with a computer.

-To identify what complaints are observed as a result of changes in body posture.

The following statistical methods have been applied to perform the tasks formulated in the above mentioned way:

- frequency analysis - one-dimensional and two-dimensional;

- variation analysis;

- cluster analysis.

The results are presented in table and Microsoft Office (Word, Excel) is used. The data is processed and an IBM SPSS for Windows, v. 19.0 software package for statistics is used.

\section{RESULTS}

According to the "age" criterion, the distribution of the participants in the survey is different from the normal one (One-Sample Kolmogorov-Smirnov Test sig $=0.000, \alpha=$ $0.05)$. The youngest respondent is 17 years old and the oldest is 55 . The analysis of the data shows the presence of significantly deviating values related to the studied criterion (Table 1). This gives us reason to accept as a measure of the middle age value (central trend) the value of the median - 21 years (arithmetic average - 25 years). The most common age value among respondents is 20 years.

The group of respondents formed by criterion "age" is not homogeneous (coefficient of variation $\mathrm{V}=32.90 \%$ ). This makes it possible to study individuals from different age groups, which adds value to the conclusions and results of the analysis (Table 1).

Table 1. Distribution of students by age

\begin{tabular}{|c|c|c|}
\hline Age range. & Percentage & Person \\
\hline up to 25 years & $76.3 \%$ & 55 \\
\hline from 26 to 35 years & $11.2 \%$ & 8 \\
\hline from 36 to 44 years & $5.6 \%$ & 4 \\
\hline over 44 years & $6.9 \%$ & 5 \\
\hline
\end{tabular}


According to the gender criterion, 29.2\% of the participants in the survey are men, and the remaining $70.8 \%$ are women.

To the question "What computer do you use most often?" the survey offers 3 possible answers as follows:

-Desktop computer (the main unit is intended to be located in a permanent location);

-Desktop and portable, with an approximately equal time of use;

-Portable computer (designed specifically for portability and to be operated for extended periods of time either with or without a direct connection to an AC power source).

Two-thirds of respondents said they preferred a laptop to a desktop computer: $77,7 \%$ - desktop computer, $13,8 \%$ - desktop and portable computers with an approximately equal time of use, $8,3 \%$-a portable computer designed specifically for portability. The twodimensional frequency analysis according to the criteria "Preferred computer type" and "Age" shows that the participants in the survey up to 25 years of age generally use all three types of computers. Respondents in the 26-35 age group spend the most time using a desktop computer, which does not move often from its place, or a portable computer, the type of laptop they use in different places. Respondents between the ages of 36 and 44 use a desktop and laptop computer with approximately equal timeof use. Respondents belonging to the age group over 44 mostly give their preferences to the desktop computer.

Regarding the question " How many hours per day do you spend staring at a screen? (without including breaks for rest)?":

The largest is the share of those who use a computer without interruption between 4 and 6 hours per day $-38.9 \%$, followed by those using a computer from 6 to 8 hours per day $-26.4 \%$, users in the group of "less than 4 hours" $23.6 \%$, followed by those who use computers more than 12 hours per day $-6.9 \%$. The lowest percentage of digital devices users represent those working between 8 and 12 hours $-4.2 \%$. Respondents'answers to the question "How is the place where you work with a computer equipped?" are grouped as follows:

For the correct posture in everyday work with a computer, not least in importance is the equipment of the workplace. The percentage distribution, according to the type of chair, shows that $18 \%$ of the surveyed students use a height-adjustable desk and chair with backrest. Also $18 \%$ use a non-adjustable desk and a height-adjustable chair with backrest. $19.7 \%$ of the respondents are equipped with a low table (a type of coffee table) and a sofa / armchair or a stool for sitting.

$29 \%$ of the students work at a table (for example, for dining) and on a non-adjustable chair with a backrest. $8.3 \%$ of the respondents declare working at a high table (bar counter type) and on a high chair without a backrest.

These results show that three-quarters of students work with a computer in inappropriate conditions that will inevitably have a negative impact on their musculoskeletal system and their health. A study by K. Jacobs (9) emphasizes that in the process of ensuring healthy working conditions, targeted training for the creation of lasting work habits should be carried out in order to optimize the workplace and adapt to the needs of computer workers.

Respondents'answers to the question " What is your usual position in front of the computer?" are grouped as follows:

$33.4 \%$ of the respondents confirm that when they use a computer, their body posture is sedentary at all times. The respondents of the next group of $22.2 \%$ claim to combine sitting and standing position in a 2:1 ratio (sitting for 1 hour, and then standing for 30 minutes). Only $13.8 \%$ of the respondents declare that their typical position when working with a computer is standing all the time. $30.6 \%$ define their usual position as different from the indicated ones.

From the results obtained through this study we can conclude that the majority of respondents define their typical position when working with a computer as constantly sitting or different from standing. $18.30 \%$ of the respondents confirm that they prefer to work twice as long as sitting rather than standing, defining their usual position as combined. Therefore, we can conclude that in addition to the preferred sitting position, most of the time surveyed students spend in front of the computer is in a sitting position and / or other than standing.

Question №7 "Do you use a specialized program to monitor the duration of your work 
with a computer?" The answers to this question show that only $2.8 \%$ of students use a specialized program for proper use of rest when working with a computer. $41.6 \%$ of the respondents determine the amount of time to rest at their own discretion and 55.6\% do not use breaks when working with a computer.

The next question, "The top of your computer screen is at the level of ...(choices)?" examines how usual positions affect the user's vision (Table 2).
The highest percentage of respondents answer that the level of the upper edge of the computer screen while working is at the level of the nose $-31.30 \%$, followed by the level of the chin $29.80 \%$ and the level of the eyes $-22,90 \%$. A total of $16 \%$ of the students surveyed set the shoulders and chest as levels at the top of the computer screen, which is a prerequisite for increased tear evaporation and dry eyes.

Table 2. Results for the position of the upper edge of the computer screen relative to the user's body

\begin{tabular}{|c|c|c|}
\hline Level of the upper edge of the screen & $\begin{array}{c}\text { Percentage } \\
\text { distribution }\end{array}$ & Person \\
\hline Eyes & $22.90 \%$ & 16 \\
\hline Nose & $31.30 \%$ & 23 \\
\hline Chin & $29.80 \%$ & 22 \\
\hline Shoulders & $8.40 \%$ & 6 \\
\hline Chest & $7.60 \%$ & 5 \\
\hline
\end{tabular}

From the point of view of vision preserving, the optimal levels at which the upper edge of the computer screen needs to be located are: the eyes, the nose and the chin. A high percentage of students confirm these levels $84.00 \%$.
The capabilities of the workplace equipment, such as the adjustable chair, allow the computer screen to be optimally positioned. Of interest is the question of the extent to which the surveyed students make full use of the functionality of the equipment in their workplace, in terms of the location of the computer screen (Table 3).

Table 3. Cross table Location of the computer screen in relation to the available equipment

\begin{tabular}{|c|c|c|c|c|c|c|}
\hline EQUIPMENT & \multicolumn{6}{|c|}{ LEVEL OF THE UPPER EDGE OF THE SCREEN } \\
\hline & EYES & NOSE & CHIN & SHOULDERS & CHEST & TOTAL \\
\hline $\begin{array}{l}\text { Height- } \\
\text { adjustable desk } \\
\text { and chair with } \\
\text { backrest }\end{array}$ & $\begin{array}{c}7 \\
18 \%\end{array}$ & $\begin{array}{c}7 \\
33.3 \%\end{array}$ & $\begin{array}{c}7 \\
33.3 \%\end{array}$ & - & - & $\begin{array}{c}21 \\
28.98 \%\end{array}$ \\
\hline $\begin{array}{l}\text { Non-adjustable } \\
\text { desk and height- } \\
\text { adjustable chair } \\
\text { with backrest }\end{array}$ & $\begin{array}{c}5 \\
25.00 \%\end{array}$ & $\begin{array}{c}5 \\
25.00 \%\end{array}$ & $\begin{array}{c}8 \\
40.00 \%\end{array}$ & $\begin{array}{c}2 \\
10.00 \%\end{array}$ & - & $\begin{array}{c}20 \\
27.6 \%\end{array}$ \\
\hline $\begin{array}{l}\text { Dining table and } \\
\text { non-adjustable } \\
\text { chair with } \\
\text { backrest }\end{array}$ & $\begin{array}{c}13 \\
25.50 \%\end{array}$ & $\begin{array}{c}21 \\
41.20 \%\end{array}$ & $\begin{array}{c}10 \\
19.60 \%\end{array}$ & $\begin{array}{c}3 \\
5.90 \%\end{array}$ & $\begin{array}{c}4 \\
7.80 \%\end{array}$ & $\begin{array}{c}41 \\
56.58 \%\end{array}$ \\
\hline $\begin{array}{l}\text { High table (bar } \\
\text { counter type) } \\
\text { and high chair } \\
\text { without back }\end{array}$ & & $\begin{array}{c}4 \\
57.10 \%\end{array}$ & $\begin{array}{c}2 \\
28.60 \%\end{array}$ & $\begin{array}{c}1 \\
14.30 \%\end{array}$ & & $\begin{array}{c}7 \\
9.6 \%\end{array}$ \\
\hline $\begin{array}{l}\text { Low (coffee } \\
\text { table type) table } \\
\text { and sofa / } \\
\text { armchair or stool } \\
\text { for sitting }\end{array}$ & $\begin{array}{c}4 \\
14.80 \%\end{array}$ & $\begin{array}{c}7 \\
25.90 \%\end{array}$ & $\begin{array}{c}6 \\
22.20 \%\end{array}$ & $\begin{array}{c}6 \\
22.20 \%\end{array}$ & $\begin{array}{c}4 \\
14.80 \%\end{array}$ & $\begin{array}{c}27 \\
37.26 \%\end{array}$ \\
\hline
\end{tabular}


The data in the table show that students who have a height-adjustable chair and desk make optimal use of their capabilities, adjusting their position so that the computer screen lies at eye level, nose and chin. $90 \%$ of the respondents do not have the opportunity to adjust the level of the desk, but they have the opportunity to change the height of the chair and use it optimally. Only in $10 \%$ of the surveyed users the upper level of the computer screen is located at the level of the shoulders.

$13.70 \%$ of the group of students who do not have the opportunity to use the possibilities of the adjustable chair have placed the computer screen on a dining table at the level of their shoulders and chest.

$14.30 \%$ of those who have equipped their workplace with a high table (bar counter type) and a high chair without a backrest have their screen at shoulder level. The remaining $85.70 \%$ confirm that the position of the upper edge of their computer is at the level of the nose and chin.

The percentage of students incorrectly positioning the screen, who use a low (coffee type) table and sofa / armchair or stool for sitting, as part of their workplace is the highest $-37.00 \%$.

n conclusion, we can summarise that students who are equipped with a hight-adjusting table and a hight-adjusting chair use these opportunities optimally in terms of achieving the right position for the computer screen to their own body proportions.

Question №9 "What is the distance from your face to your computer screen?"

The survey offers 3 possible answers as follows:

- From 55 to $70 \mathrm{~cm}$;

- From 40 to $55 \mathrm{~cm}$;

- Less than $40 \mathrm{~cm}$ or more than $70 \mathrm{~cm}$.

From a health point of view, the appropriate distance from the face to the computer screen is from 55 to $70 \mathrm{~cm}$. It should be noted that $51.3 \%$ of the surveyed students work at a distance of 40 to $55 \mathrm{~cm}$ from the screen of their computers, $25 \%$ work in the range of less than $40 \mathrm{~cm}$ or more than $70 \mathrm{~cm}$.

This creates preconditions for the risk of eye problems as a consequence of long-term work with a computer (Table 4).

Table 4. Results from the answers to the question №9

\begin{tabular}{|c|c|c|}
\hline Distance from the face to the screen & $\begin{array}{c}\text { Percentage } \\
\text { Distribution }\end{array}$ & Person \\
\hline From 55 to $70 \mathrm{~cm}$ & $23.7 \%$ & 17 \\
\hline From 40 to $55 \mathrm{~cm}$ & $51.3 \%$ & 37 \\
\hline Less than $40 \mathrm{~cm}$ or more than $70 \mathrm{~cm}$ & $25 \%$ & 16 \\
\hline
\end{tabular}

Question №10 "For how many years have you been using a computer regularly (at least 4 days a week)?"

$22.2 \%$ of the students have used a computer for up to two years. The highest percentage of $34.7 \%$ represents the group of computer users having used regularly computers from two to five years. The group of computer users having worked with computers for six to twelve years follows the first group with a small difference - $33.4 \%$. Those who have worked for over 13 years represent $6.9 \%$ and only one student has worked with computers for over twenty years $-2.8 \%$.

Question №11 "Do you do moving / stretching exercises while using a computer?"
The highest is the percentage of respondents that do not do exercises for movement and / or stretching while using a computer - $36.1 \%$. Students representing $30.6 \%$ make exercises for movement once a day while $12.5 \%$ do active training after using a computer several times a week. Those who actively train several times a day represent $20.8 \%$. None of the respondents indicates that they train only once a week.

In general, the results show a low degree of muscle activity of students during and after working with a computer $-36.1 \%$.

Question № 12. "In which part of your body do you feel pain?" 
The results of the answers to this question show the health status of the students.
The survey includes ten areas in which pain may occur as a result of improper working position when working with a computer (Table 5).

Table 5. Results from the identification of pain location

\begin{tabular}{|l|l|l|l|l|l|c|l|l|l|c|}
\hline area & Head & $\begin{array}{l}\text { Cervical } \\
\text { region }\end{array}$ & $\begin{array}{l}\text { Thoracic } \\
\text { section }\end{array}$ & Shoulders & $\begin{array}{l}\text { Lumbar } \\
\text { section }\end{array}$ & Elbows & Palms & $\begin{array}{l}\text { Sacral } \\
\text { region }\end{array}$ & Knees & Drumsticks \\
\hline $\begin{array}{l}\text { perce } \\
\text { ntage }\end{array}$ & $\begin{array}{l}34.7 \\
\%\end{array}$ & $63.8 \%$ & $25 \%$ & $31.9 \%$ & $50 \%$ & $12.5 \%$ & $\begin{array}{l}15.2 \\
\%\end{array}$ & $50 \%$ & $\begin{array}{l}26.3 \\
\%\end{array}$ & $9.7 \%$ \\
\hline Person & 25 & 46 & 18 & 23 & 36 & 9 & 11 & 36 & 19 & 7 \\
\hline
\end{tabular}

While $34.7 \%$ of the respondents confirm the presence of pain and discomfort in the region of head and shoulders, $50 \%$ have problems in the lumbar region, and this percentage increases to $63.8 \%$ concerning the cervical region. Every third respondent experiences varying degrees of cervical pain. An innovative tool for analyzing this type of process is the neural network (10).

\section{DISCUSSION}

The initiation of distance learning in connection with the set in pandemic has increased many times the utilization of software technology by young people. The implemented analysis has shown that $38.9 \%$ of the tested students have used their computers nonstop between 4-6 hours. A computer has become an inseparable part of students' work and daily life. It has been found from the analysis that the preferable mobile device among the inquired students is laptop. Although young people have access to modern sources of proper ergonomic equipment at working with computers, a small number of them have conformed to these requirements. The percentage distribution according to type of chair has shown that $67.40 \%$ of the inquired have used unadjusted chairs without backs during their work. $69 \%$ of the students have worked at unsuitable distance from the screen to the face, causing preconditions for visual problems and postural disturbances.

The results from the study have shown that the usual position of students, working at computers, is a seat or leg. One of the reasons is the lack of special equipment for the bigger part of the students. It has made the impression that the students, who have equipment with the possibility for its height regulation, have used it with optimum capacity, setting the computer screen on the level of the eyes, nose or chin.
Young people still do not have inveterate diseases and underestimate the negative influence of incorrect working pose on their organisms. Students have manifested a low degree of muscle activity after working at a computer; only $36.1 \%$ have recovered by sports activities. On the other hand, the imposed quarantine has limited the possibilities of people to do sports. Though young people have access to information only one third of the students keep the ergonomic requirements. It is necessary to be paid attention purposefully on students for the hidden risks by exposure in front of the software technology. It has been confirmed by the received data of the inquiry. There has been observed an alarming tendency for occurrence of pains in the cervical and lumbar regions of the spinal column, shoulders, wrists and appearance of visual problems.

Epidemiologic situation in our country gives us reason to suppose continuation of distance learning even during the next school year.

It is desirable to be organized a seminar for the students to be acquainted with the ergonomic requirements while working at computers as well as presentation of kinesitherapeutic complexes for prevention of postoral disturbances.

\section{THE WEKNESSES OF THE STUDY}

This is a pilot study that includes a small number of participants and is addressing only the students from the Medical University of Sofia There should be a follow-up and additional evaluation is needed.

\section{CONCLUSIONS}

Students have a preference for a mobile computing device that they can use anywhere. However, this leads to certain health risks, because the correct position of the body when working with a computer is systematically neglected, the distance between the device and the eyes is reduced, which hampers the visual 
analyzer and will inevitably lead to visual impairment.

The lack of physical activity and increased time of stay in front of a computer in connection with distance learning is a serious prerequisite for postural disorders.

It is necessary to implement various measures to improve motor activity of students as well as to raise their awareness of the risks of working too long with computers.

\section{REFERENCES}

1. Doŭchinov Sv. Zrenie $\mathrm{v}$ usloviya na karantina, Tvoyat biznes, april, 2020

2. Rasoulzadeh Y. and R. Gholamnia, "Effectiveness of an ergonomics training program on decreasing work-related musculoskeletal disorders risk among video display terminals users," Health Promotion Perspectives, vol. 21, no. 1, pp. 89-95, 2012.

3. Barisone, M., Annamaria Bagnasco, Giuseppe Aleo at al. The effectiveness of web-based learning in supporting the development of nursing students' practical skills during clinical placements: $A$ qualitative study Nurse Education in Practice, Volume 37, pp. 56-61, https://doi.org/10.1016/j.nepr.2019.02.09

4. Akinbinu T., Mashalla Y. Impact of computer tehnolodgy on health: Computer
Vision Sindrome, Academic Journals, Vol 5 (3), November 2014.

5. Stanchev, V., Organizatsiya na rabotnoto myasto i zdravni oplakvaniya pri rabota $\mathrm{S}$ videodisplě, ZDRAVE I BEZOPASNOST PRI RABOTA Tom 1, knizhka 1, s.35 - 42, 2015.

6. Kozeis N. Impact of computer use on children's vision. Hippokratia.;13:2301.2009.

7. Balichev, YU., T. Tat'ozov, Kr. Kostadinova, St. Shpangenbelg. Vliyanieto na faktorite na virtualnata sreda vŭrkhu zdraveto na uchenitsite, zhiveeshti $\mathrm{v}$ razlichni po golemiia naseleni mesta $\mathrm{v}$ Bŭlgariya, Prakticheska Pediatriya, pp.1923, 04.12.2017.

8. Huhman M, Lowry R, Lee SM, et al, , 'Physical activity and screen time: trends in US children aged 9 to 13 years, 20022006', Journal of Physical Activity and Health, vol. 9, no. 4, pp. 508-515, 2012.

9. Jacobs K., Kaldenberg J., Markowitz J., Wuest E., Hellman M., Umez-Eronini A., Arsenault M., Walker B., Hall V., Ciccarelli M., Parsons R., Barr A., An ergonomics training program for student notebook computer users: preliminary outcomes of a six-year cohort study, Work, 44(2):221-30, 2013;

10.Konchev, M., Sŭvremenni metodi za analiz na danni za distantsionna forma na obuchenie, Sofiya, NSA Pres. Konchev. M., 2018. 